\title{
The Missing Piece: Human-Driven Design and Research in ICT and Development
}

\author{
Paul Brand (RiOS Institute), Anke Schwittay (RiOS Institute, UC Berkeley)
}

\begin{abstract}
ICTD projects are usually driven along the three axes of technological innovation, development programs or new market creation. These drivers have to be complemented by a focus on the people served by ICT, and their needs. In this paper, we argue for the importance of human-driven design and research (HDDR) to take into account the four human dimensions of ICT: local practices; participatory design processes; sociocultural contexts, and political conditions. Building on our ethnographic and design research on the LINCOS project in Costa Rica and Hewlett-Packard's e-Inclusion program, we show how Lincos' success was impeded by its inattention to human design features, the deployment of a neoliberal discourse of community appropriation, and the market-driven focus of e-Inclusion. We conclude by situating ICTD in the larger context of human development, and with reflections on what constitutes sustainable, successful ICTD projects.
\end{abstract}

Index Terms: design methodology, social issues, human factors, user interfaces, IT for developing regions.

When we arrived in San Marcos, Costa Rica, in the spring of 2003 to conduct ethnographic and design research on an ICTD project that at the time of its launch in March 1999 was celebrated as Digital Town Centers that could link "underdeveloped region of the world ... to the latest educational, medical, commerce and arts services," we were in for a surprise (MIT press release). The container, about which we had heard so much, full of computers, printers, scanners, projectors and telemedical equipment, hooked up to the internet via a satellite connection, and powered by solar energy, was completely shut and looked utterly abandoned among the coffee plants surrounding it. Only the faded pictures of smiling adults posing for the camera, and of eager children sitting in front of brand new computers, which were peeling off from the container's outside, spoke of its former glory.

Over the next few months, we pieced together what had happened to this "community center of the $21^{\text {st }}$ century," as Jose Maria Figueres, former President of Costa Rica, liked to call the container. Figueres, former chairman of the United Nation's ICT Task Force, is an ardent believer in the benefits of ICT for developing countries. He also founded and led the Costa Rican Foundation for Sustainable Development (Entebbe), which ran the project at whose no-longer beating heart we were looking in San Marcos. This was the so-called Little Intelligent Communities, better known by its acronym of LINCOS, a co-creation of Entebbe, the Massachusetts Institute for Technology's Media Lab, and the Instituto Technologico de Costa Rica (ITCR), Costa Rica' foremost technological university. Lincos was also supported by a large number of transnational high-tech corporations, among them HP, Intel, Alcatel, Microsoft and Motorola.

\section{COMMUNITY TELECENTERS}

At the time of its inception, Lincos was a high-profile community telecenter project, aiming to "expand the opportunities for community development by prioritizing access and utilization of information and communication technologies, mainly in isolated and rural communities" (http://www.lincos. net/ webpages/english/general.html). Telecenters have been a popular way of providing communities with computer and internet access, predominantly on a non-profit basis. However, as research by the World Resource Institute and the World Bank's Development Gateway has shown, their success and survival is far from guaranteed [1], [2].

One of the reasons is that "telecenters are a 19th century industrial response to a social and communications problem. They deliver end-products from one economy to another, then require the recipient economy to adapt to the technology before any benefits are delivered" [3]. Earl Mardle argues that the telecenter model operates differently from the internet model it is supposed to serve, a misfit between means and ends that contributes to telecenters' frequent failure.

Lincos was no exception, in spite of a high-profile and well-financed start. The project aimed to drop recycled shipping containers filled with high-tech into previously unconnected areas around the world. As such, Lincos presented a foremost example of a Western technology export Furthermore, because telecenters are one of the most ubiquitous ways of making available access to and training in ICT, they provide a good context in which to examine the workings of ICT in development. In the case of Lincos, the global technology dreams of its creators at the MIT Media Lab were never realized. An exploration of the reasons for this failure reveals the shortcomings of common assumptions of ICTD projects, as well as the importance of human-driven design and research (HDDR).

\section{HUMAN-DRIVEN DESIGN AND RESEARCH}

ICTD must strive for a balance between the pull exerted by local wants and aspirations, and the push coming from global institutional and technological forces. Furthermore, the use of 
ICT in development must be driven by human needs, complementing appropriate technological innovation, development plans, or consumption creation. This focus on human needs and aspirations creates a broader frame of reference that goes beyond even the users of technology, since it leaves room for the possibility that for certain groups ICT is not (at least at the moment) an appropriate solution to their problems.

Focusing on real human needs also means putting aside Western assumptions about the uses and benefits of ICTD. The question becomes instead how fitting it is to transplant technologies and products developed in a western, mostly urban context, into developing countries and predominantly rural areas. Issues such as environmental impact, cultural appropriateness, consumption practices and technological infrastructures all need to be taken into account.

To give an example of the latter, when exporting a certain technology, it is often necessary to also export part of the economy that produced this technology and is needed to sustain it. As a result, "we hand this over-capitalized, soupedup, expensive system over to the local community and expect them to make it "economically viable" [3]. As anthropological studies of the introduction of Western technologies into non-Western societies have shown, instead of local self-sufficiency, this transfer creates a dependency on external sources for continued financial and technological support and upkeep.

In this paper, we propose HDDR as one promising avenue to develop appropriate and sustainable technology solutions. By HDDR we mean projects whose design and innovations are driven by in-depth knowledge about local conditions. This knowledge is gained from long-term, human-centered research similar to anthropological participant-observation, and a participatory community design process. This combination of research, design and innovation results in the four dimensions of HDDR: local practices; participatory design processes; socio-cultural contexts, and political conditions (adapted from [4]).

In the remainder of this paper we want to show how the use of HDDR can productively address some of the gaps in ICTD projects. To do so, we draw on our multiyear ethnographic and design research on the Lincos project in Costa Rica and HP's e-Inclusion program.

\section{LITTLE INTELLIGENT COMMUNITIES}

Lincos started when President Jose Maria Figueres approached Alex Pentland at the MIT Media Lab with his idea to create a $21^{\text {st }}$ century digital town center in late 1998 . As the project took shape over the next few months, ITCR became involved in the design of the center, which eventually was housed in a converted industrial shipping container. The first prototypes of the container were presented to the world in early 1999, and one year later, the first two functional Lincos containers were outfitted by HP. The company used the project to get its own ambitious global e-Inclusion Solutions program off the ground.

One of these container is still stationed at ITCR in Cartago, where it serves as the Monitoring and Business Development Center for the existing Lincos centers. The second container was installed in El Rodeo, a marginalized neighborhood of San Marcos de Tarrazu. This is a town of about 10,000 people located a bumpy two-hour drive south of the Costa Rican capital of San Jose, in mountains green with coffee plants. San Marcos was chosen because of its easy reach from San Jose; its rural character and economy; its lack of ICT; Figueres' family ties to the area, and the initiative of a local woman to bring the container to Rodeo.

The container opened in August 2000 to great fanfare. Five hundred people attended the inauguration, including Alex Pentland from MIT Media Lab, Alejandro Cruz, ITCR's rector, President Figueres, and Carlos Reina, the former President of Honduras, who said that he would like to bring the project to his country [5]. According to local residents, the self-esteem of the people in Rodeo rose, as they saw their neighborhood valued for the first time. This was also a result of receiving the many international visitors the container attracted. Furthermore, local schoolchildren were trained in computer use, and older students and adults attended afternoon and night classes. People also used the container for email, web searches and computer games.

In spite of these auspicious beginnings, the container was closed in November 2002. We heard various explanations for this closure, from Lincos officials, employees and operators, and from residents of San Marcos and Rodeo. Once the container's support from Entebbe had run out and its operators had begun to charge for its services, fewer people came. Some stayed away because they could not afford to pay; others because they had developed an expectation of using the container for free. In May 2002 the container could not afford its expensive satellite hookup anymore and replaced it with a much slower phone line. By that time, former Lincos students had opened an internet café in the center of San Marcos, and many people did not make the strenuous hike to Rodeo anymore. The final blow came when in November 2002, the container was broken into in the middle of the night and robbed of all but one computer.

There were other, less obvious, reasons that contributed to the demise of the container in Rodeo, and the Lincos project in its original intentions in Costa Rica. Most important among them were inattention to human design features; the deployment of a neoliberal discourse of community appropriation, and the market-driven focus of HP's eInclusion work. We will start our discussion by examining the shortcomings of Lincos' defining characteristic - the container itself.

\section{DESIGN MATTERS}

As socially and morally involved designers, we must address ourselves to the needs of a world with its back against the wall.

\section{Victor Papanek, Design for the Real World}

According to the website of MIT Media Lab's Unwired: Unwiring the World initiative, of which Lincos was a project, 
"the main body of the Lincos digital town center is a standard 20 foot ISO shipping container that has terminated its 'shipping life' because of metal fatigue" (http://www. media.mit.edu/unwired/center.html).

\section{Unwiring the world}

A standard industrial steel shipping container measures 20' (6.058m) L x 8' (2.438m) W x 8.5' (2.591m) H, producing an approximate volume of 1170 cubic feet ( 33 cubic meters).

These containers are designed to transport up to 20-ton packet units at a time. As the backbone of the global economy's land and sea shipping system, 95 percent of the worlds' products, goods and materials are shipped in containers.

To return to the Unwiring the World website, "many different types of structures were considered, including completely distributed ones, and the pros and cons of the container itself were discussed. In the end the most promising design was a relatively unmodified container, surrounded and covered by a tensile fabric structure. Such structures have substantial advantages:

(1) They are easily and economically available on the market, and there is a world wide infrastructure in place for their transportation, which will facilitate deployment to remote areas once converted.

(2) They ensure protection and security of equipment inside.

(3) They are suitable for 'assembly line' conversion within the country they will serve, to maximize use of local materials.

(4) They have very sophisticated solar properties, so that power requirements are minimal."

This $20 \times 8$ feet steel container was to house a computer classroom, an information/service center, a video conference area, and a telemedicine room. This shows that the design intention was to house technology and system solutions, not the children and adults using it. Considerations of appropriate community space, aesthetics, pedagogy and culture were absent from this intention.

The design was also not sensitive to the geography and the challenging tropical climate of the sites in which the containers were installed. They could thus not accommodate the sometimes $100 \mathrm{~F}$ and 80 percent humidity that reigned in some of these sites. These unbearable conditions were augmented by the heat generated by the electronic equipment, which in turn suffered from the lack of ventilation and air conditioning in most of the containers. When an a/c system was installed in a new container in Costa Rica's hot and humid banana belt, according to Lincos' executive director at Entebbe this went counter to the project's original intention of environmental sustainability. The latter was to be achieved through the use of solar panels, which were not installed in a single container however.

\section{Technological colonization}

The co-designer of the container at ITCR described it as resembling "an alien spaceship dropping from the sky." He thereby admitted that the container was an invasive object, culturally and physically foreign to the people of Rodeo. Rather than using local designs and materials, the container was obviously conceived at and brought in from the outside.

For the designer, this reflected the external influences that ICT introduces to a place, which he described as "cultural colonization" and "culture shock." Mothers" recollections of their wonder at seeing their children touch a keyboard for the first time, and of later concerns about them spending all their time at the container playing computer games, gave expression to this ambivalence about the benefits of ICT.

Trying to minimize this tension was a difficult undertaking, according to the designer, because "technology is blind, it does not care about its effects." It might be true that a computer is an alien object in most places of the world, but the designer's conclusion neglected the possibility of situating it within locally-appropriate contexts that include the physical space surrounding it. Presenting a computer inside a metal container does not contribute to the demystification of ICT or its local appropriation [6].

To be sure, as the co-creator of the container, alongside MIT's Media Lab, the designer had much invested in its form. Therefore, in spite of his reservations, he presented a long list of advantages that the containers and its contents provided for the production and installation of Lincos centers. Not surprisingly, his reasons for the choice of the container echoed the rationales given on the Media Lab website.

The container's apparent economical price and inexpensive improvements gave economic concerns precedence over cultural ones, which in many places delimit containers as a space for cargo rather than people. It was strong and thought to be safe, until the robbery in Rodeo. The trademark white, star-shaped tensile structure that was supposed to cover the container could easily be branded as modern and innovative; it also protected the container and its contents against the elements. However, the tent was difficult to put and keep up, and thus most containers lost their covers early on and were exposed to merciless sun or pounding rain. (We saw students at ITCR mopping gallons of water from a metal container filled with electronic equipment, after a storm had blown down the tent.)

All of this equipment, and the tent, could be put inside the container and transported using already existing infrastructures. There was thus at least the potential to colonize remote places all over the developing world, as imagined by the container's creators and supporters. As an (ideally) self-contained unit, the container constituted a potentially global object. However, these same characteristics stood in the way of localizing the container in particular sites. It always remained a disembedded object in Rodeo, which continued to remind people there of its foreign origins. The container also betrayed its own temporary character, and indeed was eventually removed from Rodeo.

\section{Brick-and-Mortar}

The first large-scale deployment of Lincos was supposed to be in the Dominican Republic, where the government 
contracted Entebbe for the installation of sixty centers, as part of a national Plan against Poverty [6]. This number was later reduced to thirty, and the last fifteen of these were installed by the Dominican Ministry of Education rather than by Entebbe.

More importantly, after installing five containers, the government decided to house the Lincos centers in ordinary brick-and-mortar buildings. According to the designer at ITCR, government officials explained this by arguing that in their country, containers were associated with poor people. This cultural assumption kept people from visiting the Lincos centers. In addition, it was the same misfit between the foreign design and local contexts that caused people to stay away from the cramped, overheated space, and the staff of one center to go on strike for six months [6].

From a design process point of view, Lincos could thus be viewed as a failure from the beginning. Even with the participation of the leading Costa Rican technological university, the Lincos container was the brainchild of a group of Western and Western-trained technocrats, professors and their research students. They did not include indigenous designs, materials or needs into their broader design methodology, and the product of this methodology was ultimately rejected by the constituents the designers were supposed to serve.

What is needed instead of externally-imposed technology fixes are methods of co-design, which "require using local knowledge to understand the appropriateness of certain technologies over others" [7]. The TIER project at UC Berkeley is one example of technologists trying to create locally appropriate ICT, rather than using off-the-shelf Western imports, in order to accommodate local technological infrastructures. The increased impact of resulting projects can further be augmented by attention to local human practices and social contexts, which HDDR facilitates.

The second reason for the demise of the Rodeo container, namely the lack of involvement of its users in its operations and maintenance, stemmed in part from these design issues.

\section{COMMUNITY APPROPRIATION}

Most people we talked to in San Marcos and at Entebbe argued that it was the community's responsibility to rally around the container, if they wanted it reopened after the robbery. By the community, they usually meant the inhabitants of Rodeo, especially the ones who had used the container. The latter were asked in a meeting to show willingness and initiative by raising money for a security system and a fence. (These should have been there in the first place, but Entebbe never spent the money). In accordance with a neoliberal logic, 'the community' thereby became a space of action exerted to manage itself and take responsibility for its own development [8]. This line of reasoning, which is widespread among development practitioners, elides several important questions.

\section{Definitions of community}

One is the very definition of community, a concept that derives its current power from its ubiquitous but nebulous use [9]. Who is considered a member of a particular community can change throughout time. In this way, invocations of community can be used as a means of exclusion.

When it came to initiatives to reopen the Rodeo container, the community encompassed people of Rodeo first and foremost. However, when it became obvious that no action would be forthcoming, Lincos' director at Entebbe started talking about the community as the people of San Marcos. This allowed him to argue that because of the latters' greater affluence, they did not really need the container. In addition, the internet café in the center of San Marcos showed that the container had made itself obsolete. It had fulfilled its mission of bringing ICT access to Rodeo, and could thus be removed. This is exactly what happened, disregarding the fact that people in Rodeo could not afford to use the internet café.

The container was moved to a more central location, where it became a small business development center. This was in line with the general shift of Lincos: Second Generation, as the reinvented Lincos project is now called, from free, broadbased ICT education, to providing e-services to selected, promising individuals and business clients who are able to pay for them. In this way, Lincos itself has undergone a neoliberal reorientation, in order to ensure its own survival.

\section{Local ownership}

According to one Entebbe employee, the reasons why people in Rodeo did not mobilize sufficiently to get the container reopened were manifold. "They always regarded the container as Entebbe's project, also because Entebbe used it as a showcase. It was the star container and brought people from all over the world. But the community never saw it as theirs and they never learned to take care of it."

This disconnect had started with the installation of the container without much local consultation. It was only after the container's arrival that a local Lincos association had been formed. Furthermore, Lincos' connection with so many universities and companies, as evidenced by the frequent visitors from the U.S. and other countries, lent the container an air of legitimacy, worth and quality. At the same time, however, it undermined the argument that people in Rodeo should take care of the container. This seemed both an unnecessary and daunting task in the presence of so many important institutions.

A common... As argued by Klaus Stoll, Founder of the Ecuadorian telecenter initiative Casquinet, a telecenter's financial sustainability must be based on its social, cultural, political and technical sustainability [10]. This means that the center has to become a common that elicits shared ownership and support of resources. Its users need to feel empowered by and benefited from the center, whose continued existence must be in their own vital importance. This is usually achieved when the telecenter does not only provide ICT services, but contributes to the overall development and advancement of all community members. In this regard, special care has to be taken that the center does not lead to the further disenfranchisement of those most in need of information [11].

... or private property. Another proposed way to achieve local ownership has been through franchising, following the successful model of the Grameen phone ladies [7]. Here, a 
private owner/operator has a significant stake in the continued operation and success of the project, often because her livelihood depends on it. In its emphasis on Western-style models of private property and business operations, franchising stands opposite the telecenters-as-commons idea. This shows the range of possibilities that are thought to ensure the sustainability of telecenters. To this range we would add the importance of long-term, sustained and reliable donor funding.

\section{Local relevance}

The fate of the third Lincos container in Costa Rica shows the importance of local appropriation even more strongly. The container opened in April 2001 in San Joaquin de Cutris, a small, poor and isolated village close to Costa Rica's border with Nicaragua.

Before the container's installation, an anthropologist from the Universidad Nacional de Costa Rica was hired to conduct a two week Rapid Assessment Procedure (RAP). She found 'the community' eager to receive a container. However, once it was open, the container attracted only a small number of users, which subsequently dwindled further due to local personal and political divisions. The existence of these divisions points to the importance of paying attention to the changes in political and power dynamics that result from increased access to information. Potentially threatened elites need to be brought into the fold through "transition planning" [7].

The conflicts in Cutris should have been discovered during the RAP. That they were not speaks to the shortcomings of 'rapid ethnography,' one of the most popular appropriations of anthropological methodologies by institutions from foundations to corporations. These hire anthropologists or others trained in ethnographic methods as consultants and then sent them into the field for varying lengths of time, ranging from an afternoon to a month. Equipped with cameras, tape recorders and video cameras, these rapid ethnographers aim to capture the lives of their subjects as fully as possible. As 'academic' anthropologists, who frequently spend a year or longer in the field, know, even that amount of time is often not enough to fully understand the complexities of local ways of thinking and acting.

Furthermore, people are very apt at knowing the right thing to say at the right moment, especially when the prospect of receiving ICT or funding is at stake. The related observation that people often say one thing and then do another is especially true for the use of technological devices in everyday life and work practices. These are usually embodied and do not necessarily work at a conscious level that can be elicited through an hour-long conversation.

Meaningful Connections. Another reason for the closure of the Cutris container, after less than 18 months of operation, was that, in the words of one Entebbe employee, "Cutris has very basic problems and they don't need computers to solve them." When the anthropologist returned to Cutris to undertake an intermediate evaluation, people told her, "We are peasants. We have 6 th grade education and don't even know San Jose. We don't know what to do with these computers and how they could help us in our development." She concluded that "the people in Cutris did not make the connection between technology and development. For them the container was just a place to learn how to use the technology, but the more difficult part is how to make it relevant for their lives, how it fits into their lives."

This raises one of the most important issues for ICTD projects, namely the difficulties of establishing a connection between ICT and people's lives. By now, most ICTD practitioners have abandoned the assumptions of earlier digital divide projects, that merely providing access to ICT is sufficient to improve livelihoods. Instead, ICT has been recognized as a tool that can assist in all areas of development. Still, how to integrate ICT into people's lives so that it makes a meaningful difference has remained an often elusive goal.

\section{Local content}

The creation of local content is frequently seen as a step towards attaining that goal. Local content contributes to local knowledge, reinforces local connections and fulfills local demands [10]. Such local relevancy is of greater importance than access to the, English-language dominated, internet at large. Conversely, the lack of local content can augment already existing exclusions [11].

Lincos aimed to ensure the relevancy of its containers by using an educational methodology based on Seymourt Paperts's constructionist learning principles. The underlying idea is that "people learn and develop much better when engaged in meaningful projects" (www.lincos. net/webpages/english/ prioridades/ educacion/ html). To this end, the instructors working in the containers aimed to teach computer programs through specific applications ideally suggested by the student, such as learning how to type by writing a $\mathrm{CV}$, learning how to make spreadsheets by drawing up a business budget, and learning how to use presentation software by designing a school presentation. Lincos' underlying assumption was of course that learning how to navigate MS Word, Excel and Power Point was important to the people in Rodeo

While this assumption is in keeping with the agendas of many national governments to create an ICT-savvy citizenry that can contribute to the country's economic competitiveness, or with the objective of corporate high-tech sponsors to ensure the future supply of a well-trained workforce, it cannot automatically be held true for local users of telecenters.

Rather, in order to establish a meaningful connection between ICT and people's lives, HDDR focusing on the actual uses of ICT is necessary. This must go beyond focus groups and market-type studies and even rapid ethnography to an immersion into people's everyday practices. In some cases, the conclusion may indeed be that there is no need for ICT at this point in time.

However, HDDR and its findings are especially difficult to operationalize when ICTD projects, as they now often do, take the shape of Public-Private Partnerships (PPPs) that bring corporations into the fold. In the next section, we analyze how corporations' market-driven focus and profit rationality, which many ICTD practitioners see as potential guarantors for 
sustainable projects, can actually stand in the way of success.

\section{MARKET-DRIVEN DEVELOPMENT}

The market is a powerful engine of technological progressbut it is not powerful enough to create and diffuse technologies needed to eradicate poverty.

United Nations Development Report, 2001.

ICT4D must be more than ICT4 $\$$ and a quest for new markets, as some would have it at the moment. The ideas of C.K. Prahalad about "eradicating poverty through profit" [12], which have for the last few years enthralled Fortune $\mathbf{5 0 0}$ CEOs, represent a marketization of poverty that ignores its historical, political and social causes and instead focuses on transforming poverty into a market opportunity. One of the first attempts of a high-tech company to access "the fortune at the bottom of the pyramid" [12] was HP's e-Inclusion program.

\section{A new business strategy with a social mission}

According an early version of e-Inclusion's website, it was HP's participation in Lincos that inspired the company to establish its ambitious e-Inclusion program. This was positioned as a "new business strategy with a social mission," which aimed "to close the gap between the technologyempowered communities and the technology-excluded communities on our planet by making it profitable to do so."

However, after outfitting the first two containers and carrying out two pilot projects, HP left its collaboration with Lincos and Costa Rica to pursue opportunities in larger markets like Brazil, India and South Africa. In a personal interview, Debra Dunn, then HP's senior VP for Corporate Affairs and Global Citizenship, explained that HP's work in Costa Rica "was built around the vision of delivering services to the bottom of the pyramid and finding a viable business model for doing that." Indeed, the three HP employees who co-founded e-Inclusion in 1999/2000 wanted to work directly with the poorest of the poor, in order to develop new technologies and business models that would help eradicate poverty through profitable business ventures.

According to Dunn, the viable business model never materialized for HP in Costa Rica. No sellable products or services were developed, and the work that was taking place happened too slowly. There was also a large discrepancy between HP's hope to sell hundreds of computers to Lincos and similar organizations, and the dozen containers that actually materialized [13], [14], [15]. All of this led to HP's departure, and to its former partners in Costa Rica feeling the victims of changing corporate fashions, roadmaps and leadership.

Corporate Fashion Lincos' executive director told us how shortly after e-Inclusion's official launch at the Digital Dividend Conference in Seattle in 2000, HP's CEO Carly Fiorina had personally expressed her enthusiasm for HP's work with Lincos to him. In early 2003 , he lamented that in spite of his reminders that HP do not forget about Lincos, the company had decided to focus instead on India and South Africa. According to him, Lincos became a victim of HP following "whatever is fashionable at the moment; sometimes it's communities, sometimes poor people, sometimes new products." He felt that HP used Lincos for publicity purposes, and criticized the company and its leaders for lacking longterm commitment.

\section{Pilot projects}

The market-driven focus of HP's e-Inclusion work also became apparent in two pilot projects the company undertook in Costa Rica in the fall of 2001. Both aimed to bring about economic development by providing project participants with sources of income with the help of HP's mobile technology.

Information Brokers. The Information Broker project, developed by HP engineers in San Diego, sent young people equipped with HP PDAs door-to-door in and around San Marcos to sell internet services like email, web searches and digital photo printouts. The idea was that rather than waiting for people to come to the Lincos container, the brokers would take its services directly to the people. We cannot go into the details of the project here; suffice to say that locals liked and used it, and that most of the brokers, supported by a small HP salary and commissions, were able to earn a living from their work.

In spite of even its creator at HP judging it to have been successful [16], the project was terminated after three months. Local project participants were very disappointed by this course of events. Even though they mainly held the events of September 11, 2001 and the faltering U.S. economy responsible, they also did not exempt the company from blame. They were especially critical of broken promises of project continuation in the case of success, and of the company's abrupt departure, which left people hanging in the air and feeling bad about Lincos.

Organic Coffee Certification. HP's second pilot project aimed to equip coffee farmers transitioning to organic farming with PDAs to facilitate the extensive record keeping involved in that process. The main objective of what was called Certification and Traceability Service (CATS) was to develop a software that could be used for two-way communication between the farmers and the certification agency. The project involved students from UC Berkeley's Haas School of Business and from Incae, Costa Rica's foremost business school. According to them and their professors, it was the small number of potential users and buyers of the PDA that did not pass the threshold of HP's business and sales units. HP had also contracted a professor at a local sustainable development school, who had been working with a group of farmers on their transition to organic farming, to implement the project.

CATS never advanced to the point of testing a product in the field, and was terminated after three months without even the software having been developed. Besides the usual disappointment, the professor expressed an additional source of frustration for development project participations. He said: "I always try to put myself into the shoes of the other person. I can imagine a guy in Silicon Valley thinking, 'who is this 
professor in Atenas [the town were the project took place], saying that he can do a thing like this? It's probably too complicated for him.'. . . The problem is that nobody thinks that a Latino in the middle of nowhere can do something like this." In making these claims, the professor drew on a corporate discourse of ethnic and geopolitical hierarchies, which denies most Central Americans the creativity, intelligence, talent and hard-working nature of people in the U.S.. The former can assemble computers, but not design them.

\section{Corporate experiments}

One of e-Inclusion's co-founders voiced similar thoughts when he said that: "there is a legacy of first world companies coming with solutions to third world problems. They try to sell their stuff and then leave." He acknowledged that "we at HP are part of that legacy," which should place a greater burden on the company not to repeat it. In spite of this awareness, the corporate imperative of maximizing shareholder return predominates over the good intentions of individual managers and executives. In addition, questions of priorities and scale; the workings of HP's businesses; the objectives of its sales departments, as well as corporate assumptions about local abilities to carry out projects, led to the termination of HP's pilot projects in Costa Rica. This is also a question of leadership support, and in the summer of 2005 , the entire e-Inclusion program was terminated after a new CEO took over at HP.

The resulting feeling of disappointment by local project participants was augmented by their sense of being used for the company's "real world solutions testing" [16]. As Debra Dunn told a group of Haas students during a presentation of HP's Global Citizenship work in February 2004, "internally we talk about the i-communities [Costa Rica's successor sites in India and South Africa] as experiments, but not to governments, because they would take that the wrong way." The sentiment holds equally true for pilot project participants.

This language of experiments and "living laboratories" [17] reveals the instrumental nature of HP's engagement with local sites in its e-Inclusion work. As Fiorina reiterated in every single of her speeches - and she greatly exploited e-Inclusion for publicity purposes - this was a matter of 'doing well by doing good.' HP was thus very open about using e-Inclusion for realizing PR, advertising and marketing objectives, for new product development and for, however timid forays, into Prahalad's bottom-of-the-pyramid market.

While we appreciate such honesty, we argue that this market-driven focus ultimately impeded the success of these projects, both for local recipients and the company. Regarding the first, without long-term, sustained funding that is not tied to the vagaries of the company stock or the fates of individual project champions, most projects are not able to survive once the corporate donor departs. This leaves local project participants feeling frustrated, disappointed and used, especially when the project has been judged to be successful by all parties involved. And this in turn works counter to the corporate aims of building brand recognition and loyalty, which often drives project creation in the first place.
Most importantly, a market-driven focus of ICTD projects puts the wrong entity at their center - not the people who are supposed to benefit from them, but the objectives of the company. This disconnect raises the question of what are defined as successful ICTD projects, to which we want to turn in the conclusion of this paper.

\section{SUSTAINABLE SUCCESS}

We have argued that many ICTD projects exhibit certain features that impede their full success and sustainability. Among them is a neglect of appropriate and participatory design, on a human and a cultural scale. Often design is driven by economic and technological rather than human factors, which might lead to short-term savings but in the long run diminish the potential for ICT use and impact. Secondly, projects are often guided by a neoliberal logic of community involvement, without creating the necessary preconditions for that involvement to take place. Last but not least, many ICTD projects, especially those funded by corporations, are driven by market-oriented objectives, which stand in the way of the long-term involvement and funding necessary for sustainable projects. They also disregard the interests and inputs of local project participants.

\section{A tool for development}

As the 2001 United Nations Human Development Report, entitled 'Making New Technologies Work for Human Development' argues, ICT can be a tool for human development and the alleviation of poverty. Both are achieved through measures aimed at building equitable societies, which acknowledge poverty as the social and political problem it is.

As many critiques, including from within high-tech circles, have pointed out, this cannot be achieved through ICT. It rather calls for programs that address, to name just a few, the distribution of resources, income and wealth; health; education; food safety; government transparency; juridical reform, and infrastructural development. Rather than wholesale Western exports, these programs have to be carried out in a manner aware and respectful of local conditions.

There is no doubt that ICT, and technology in general, has an important role to play in development, and has done so throughout history. Examples abound of technologysupported advances in health, nutrition, agriculture and employment creation, and the multiplier effects that result from these improvements of human life [18]. They do not happen by default, however, but require concerted efforts by all participants in the ICTD arena to ensure that technology does not become another tool of political, economic and social exclusion, further marginalizing those most in need of human development.

ICT can, when respectful of the needs of people, societies and their cultures, play an important part in delivering better health care, education, economic, and other services. It can be a catalytic agent for accountable institutions, fairer legal systems and transparent government. It allows for increased access to information that can empower people and give them choices they did not have before. ICT cannot replace better 
trained teachers, access to health care, improved

infrastructures, equitable forms of power, and the celebration of diversity. It also cannot replace citizen involvement in civil society. All of these things are necessary to fight poverty, locally, nationally and globally. To attain them is challenging for G8 nations with all their resources, let alone for countries that are struggling with large populations living on a few dollars a day.

Indeed, ICT does not come cheap. The systems needed to support its implementation and maintenance are complex and go to the heart of our industrialized economic infrastructures and consumption habits. There is also a growing body of evidence that to bring about meaningful development, we need less Western-centric solutions.

\section{Beyond projects}

Our analysis of MIT Media Lab's LINCOS project raises the question as to whether Media Lab's latest initiatives, such as the One Laptop per Child Computer, will truly improve education in the countries whose governments have agreed to participate. Much ink has been spilled already on debating its pros and cons. Here, we only want to situate it in a long line of ICTD projects initiated by Western institutions, from governments to corporations to universities, and driven by the technological-interventionist solutions.

Successful projects are always rooted in conditions that enable local initiatives to emerge, and then provide the resources for them to grow. This entails a model of partnership that truly trusts the abilities of local people to know best what they need, rather than being provided for by development agencies, governments, or corporations. The greatest success stories come from concrete, well-defined areas of application such as healthcare. One often cited example are the Aravind Eye Hospitals in India. Here, socially-concerned, local individuals use their skills to mount long-term, sometimes lifetime, programs to improve the lives of those around them. They are supported by, often Western, entrepreneur-innovators who deploy their resources and know-how to scale home-grown solutions to real problems. This is one important role we see for Western-based technologists - to lend their expertise to local initiatives in need of technological innovation, financial resources and deployment skills.

The emphasis of these initiatives is on long-term engagement and funding, in which all collaborators agree that the foremost objective is to benefit project recipients. It should not primarily be to push a new technology, implement a development scheme, or explore a new market opportunity. The resulting programs have to be based on sound knowledge of local social, political and economic conditions, and on real rather than assumed needs and their solutions.

\section{The importance of HDDR}

HDDR provides one way of generating this knowledge, based on research, design and innovation that are driven by the practices and needs of the potential users of proposed ICTD projects.

We realize that this conclusion might not be news to many
ICTD practitioners, who have, often through trial and error, recognized the importance of paying more attention to project recipients. The current popularity of 'grassroots development,' 'participatory research' and 'community empowerment' speaks to this. All of these methods aim to involve local participants at various stages of project inception and implementation. However, they usually take the form of rapid ethnography, when what is needed is long-term participantobservation. This is also a matter of making accessible the research that has already been conducted, but sits unused in doctoral dissertations or academic volumes.

Such research, and concurrent design processes, enable ICTD practitioners to pay attention to the four dimension identified by HDDR as crucial ingredients for successful and sustainable ICTD projects: local practices; participatory design processes; socio-cultural contexts, and political conditions. It is our hope that making the tools of HDDR available to the ICTD community will result in human-driven technology projects that make a meaningful difference in the lives of their recipients and flourish long after their originators are gone.

Acknowledgements: The authors thank their hosts in Costa Rica, and colleagues and reviewers who contributed their encouragement and insights. This material is based upon work supported by the Social Science Research Council, the University of California at Berkeley and the RiOS Institute

\section{References}

[1] WRI (2004) Lessons from the Field: Overview of ICT Use in Development. http://www.digitaldividend.org/pubs/pubs_02 tele.htm

[2] "Community Telecenters: Assuring Impact and Sustainability," Development Gateway, 2003 http:/topics.developmentgateway.org/ict/sdm/previewDocument.do activeDo cumentId $=441647$

[3] E. Mardle, "Telecentres: How did we lose the Plot?" 2003. http://topics.developmentgateway.org/ict/sdm/previewDocument.do activeDo cumentId $=440944$

[4] M. Granqvist, "Assessing ICT efforts in marginalized regions from a critical social viewpoint: Learning from the case of Lincos." Undergraduate thesis, Malmö University College, 2003. http://www.funredes.org/olistica/documentos/thesismanne.pdf.

[5] El Pais, August 8, 2000.

[6] M. Granqvist, "Looking critically at ICT4Dev: The Case of Lincos," The Journal of Community Informatics, Volume 2, Issue 1, 2005.

[7] E. Brewer et al, "The Case for Technology in Developing Regions," IEEE Computer, Vol 38, Issue 6, June 2005.

[8] N. Rose, Powers of Freedom: Reframing Political Thought, Cambridge University Press, 1999.

[9] M. Joseph, Against the Romance of Community, University of Minnesota Press, 2002.

[10] K. Stoll, "Telecenters' Sustainability: What does it mean?," 2003 http:/topics.developmentgateway.org/ict/sdm/previewDocument.do activeDo cumentId $=442773$ 
[11] B. Fillips, "New Technologies and Knowledge for Sustainable Development: The Empowerment Challenge," Research in Science and Technology Studies 13, 2002.

[12] C.K. Prahalad, The Fortune at the Bottom of the Pyramid, Eradicating Poverty through Profit and Enabling Dignity and Choice through Markets. Wharton School Publications, 2005.

[13] P. Engardio and G. Smith "Smart Globalization." Business Week 8/208/27:17, 2001.

[14] D. Kirkpatrick "Great Leap Forward: Looking for Profits in Poverty." Fortune 2/5, 2001.

[15] C. Fiorina, "The Digital Ecosystem." Speech delivered at the Creating Digital Dividends Conference, Seattle, 2000 http://www.hp/com/cgi-bin/einclusion/lp/cgi

[16] S. Bossinger, "The Information Broker Concept: An Innovative, Business-driven method of Delivering Information e-Services." HP White Paper, 2002.

[17] D. Dunn, Debra and K. Yamashita, "Microcapitalism and the Megacorporation." Harvard Business Review, August 2003, 47-54.

[18] United Nations, "Human Development Report: Making New Technologies Work for Human Development." Oxford University Press, 2001 